\title{
Sediments and future climate
}

To the Editor - Glaciated areas on low- and mid-latitude mountains and in the high latitudes are highly sensitive to climate warming. In turn, glaciers can influence climate through albedo, carbon cycle and hydrological feedbacks, particularly during glacier retreat ${ }^{1,2}$. Elevated geomorphological activity associated with glacier retreat at the transition from a glacial to an interglacial period, termed 'paraglaciation', dominates deglaciated terrains - sometimes well into the succeeding interglacial ${ }^{3}$. Paraglaciation is characterized by enhanced sediment supply during the initial deglacial stages, which declines exponentially as deglaciated slopes become stabilized ${ }^{4}$. In turn, increased sediment supply to mountain valleys leads to enhanced sediment yield in outflowing rivers, and eventually at the coast. Presently, most mountain glaciers worldwide are in retreat. We argue that because of global warming and ice loss, paraglaciation will become the most significant process controlling sediment supply and landscape change in the mid- to high-latitudes over the next few hundred years.
Throughout the Holocene epoch, paraglacial sediment supply to river basins has steadily declined ${ }^{4}$. Global warming and continued ice retreat will temporarily increase paraglacial sediment supply and will lead to an increased landslide and flood hazard in mountain areas ${ }^{5}$.

Although mountain and high latitude regions are affected most, future global warming will cause dramatic changes in geomorphological systems at all latitudes, at rates and with outcomes not experienced previously in human history ${ }^{6}$. As a result, significant latitudinal shifts will take place in geomorphological processes, yielding a dominance of paraglaciation in mid- and high-latitude glaciated catchments, and causing unpredictable changes in physical, biological and human systems including glacier-fed water supply ${ }^{5}$.

At present we do not sufficiently understand the impacts of climate change on geomorphological systems or their sensitivity to such changes, which has important implications for the adaptive capacity of human systems ${ }^{6}$. For example, projections from global climate models are rarely used to drive models of geomorphological evolution in glaciated mountains. In the absence of such detailed geomorphological simulations, we may not be using the best range of metrics to evaluate climate change and its affects in such sensitive environments.

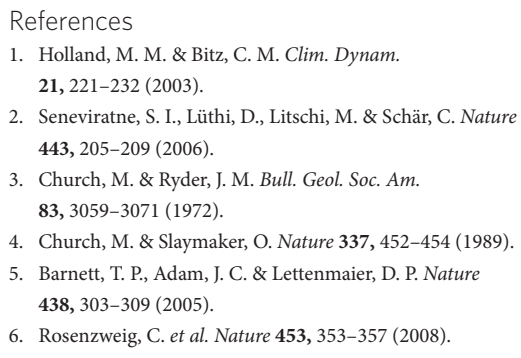

Jasper Knight and Stephan Harrison Department of Geography, University of Exeter, Cornwall Campus, Penryn, Cornwall TR10 9EZ, UK.

e-mail: j.knight@exeter.ac.uk;

stephan.harrison@exeter.ac.uk. 